\title{
DEMOGRAPHY AND SELECTION IN A POPULATION OF ARCTIC SKUAS
}

\author{
P. O'DONALD and J. W. F. DAVIS \\ Department of Genetics, University of Cambridge, Milton Road, Cambridge CB4 IXH
}

Received 8.xi.74

\section{Summary}

From demographic data of the age distributions and reproductive rates of the colour phases of the Arctic Skua, estimates are obtained of the selective coefficients of the phases in males and females. There are two main components of the selection. Dark males are favoured by sexual selection: in new pairs mating with a particular female for the first time, they breed earlier in the breeding season than other males. This gives them a selective advantage because earlier pairs fledge more chicks than pairs breeding later in the season. Pale birds of both sexes are favoured because they start breeding at an earlier age than other phases and therefore have a greater chance of surviving to breed. The component of selection in favour of pale birds is considerably greater than the component of selection in favour of dark males.

A computer model predicts that pale phases will gradually replace the darks. The gene frequency in the next generation agrees with the predicted frequency. The intrinsic rate of increase calculated for the population as a whole also predicts the actual increase in population size.

\section{INTRODUCTION}

THE selection of phenotypes in a polymorphic population can be demonstrated by observing differences in their chances of survival. But data are very difficult to obtain on the chances of survival throughout the life-history. And if estimates are to be made of the selective coefficients that measure the overall selection from one generation to the next, chances of survival and reproductive rates must be known for all stages in the life-history. Cavalli-Sforza and Bodmer (1971) estimated the selective disadvantages of certain human diseases by making assumptions about the reproductive rates. But we are not aware that there are any estimates of selection based on complete data of chances of survival and reproductive rates in animals other than man.

A colony of Arctic Skuas on Fair Isle in Shetland has been studied intensively for many years (Berry and Davis, 1970; O'Donald, 1972). O'Donald, Wedd and Davis (1974) showed that there were significant differences in the mean numbers of chicks fledged by pale, intermediate and dark-phased birds. The phases form a genetic polymorphism with dark semi-dominant to pale. O'Donald, Wedd and Davis used the differences in the mean fledging success to estimate the selective coefficients of the phases. These estimates did not allow for the effects of differences in survival or age of maturity, which, as we shall show, are the most important components of the selection.

Part of the overall selection is sexual. The males differ in their breeding times when mating with a particular female for the first time: on average 
during the breeding season, dark-phased males breed before intermediates, who breed before pales. But the females do not differ in their breeding times and nor do the males when they breed with the same female in later years. O'Donald, Wedd and Davis fitted models of sexual selection to the distributions of breeding times of males and thus estimated the female mating preferences that would produce the observed distributions. They also estimated the coefficients of sexual selection produced as a result of the differences in breeding times. As originally suggested by Darwin (1871), the selection occurs because pairs of birds that breed later in the season fledge fewer chicks on average than earlier pairs. In the new pairs alone, the selective differences between dark, intermediate and pale males are considerable; but since the new pairs represent only 36 per cent of the total, the effect of the sexual selection is correspondingly reduced.

\section{Demographic estimates of SELEGTion}

We have now analysed the data according to the age of individual birds and the mean number of chicks they fledge. We also have data on the ages at which dark, intermediate and pale birds breed for the first time. Therefore we can estimate the overall selective coefficients of the three phases of both males and females. Table 1 gives the analysis of the data on the age distributions and fledging success of the birds breeding on Fair Isle. In general the mean breeding age, which is an estimate of generation time, is calculated by the formula

$$
\begin{aligned}
T & =\sum_{x} x l_{x} b_{x} / \sum_{x} l_{x} b_{x} \\
& =R_{1} / R_{0},
\end{aligned}
$$

where $x$ is the age in years, $l_{x}$ is the proportion who survive to age $x$ and $b_{x}$ is the number of male or female offspring produced at age $x$.

Unfortunately the numbers of individuals, $n_{1}, n_{2}, n_{3}$, etc., with $1,2,3$, etc., years of breeding experience, which are given in table 1 , are not a cohort of births and cannot be used to determine the probabilities of survival, $l_{1}, l_{2}, l_{3}$, etc., by the simple formulae $l_{2} / l_{1}=n_{2} / n_{1}, l_{3} / l_{1}=n_{3} / n_{1}$. In fact $n_{1}$ is the sum of all individuals who are breeding for the first time and who have come as breeding adults to the colony in successive years. Thus

$$
n_{1}=n_{11}+n_{12}+n_{13}+\ldots,
$$

where $n_{11}, n_{12}$ and $n_{13}$ are the numbers breeding for the first time in the first, second and third years during which the colony was being studied. If $n_{21}$ and $n_{22}$ are the numbers of survivors that breed in a second year, then

$$
\begin{aligned}
& n_{2}=n_{21}+n_{22}=\left(l_{2} / l_{1}\right)\left(n_{11}+n_{12}\right) \\
& n_{3}=n_{31}=\left(l_{3} / l_{1}\right) n_{11} .
\end{aligned}
$$

An unbiassed estimate of $l_{2} / l_{1}$ is therefore

$$
l_{2} / l_{1}=\left(n_{2} / n_{1}\right)\left\{n_{1} /\left(n_{11}+n_{12}\right)\right\}
$$


TABLE 1

Total numbers of chicks fledged to individual birds breeding in successive years in the colony

\begin{tabular}{|c|c|c|c|c|c|c|c|}
\hline \multirow{4}{*}{$\begin{array}{l}\text { Phase } \\
\text { Pale }\end{array}$} & \multirow[b]{2}{*}{ Exp. } & \multicolumn{3}{|c|}{$\begin{array}{l}\text { Fledging success } \\
\text { of males }\end{array}$} & \multicolumn{3}{|c|}{$\begin{array}{l}\text { Fledging success } \\
\text { of females }\end{array}$} \\
\hline & & No. & Sum & Mean & No. & Sum & Mean \\
\hline & 1 & 22 & 15 & $0 \cdot 6818$ & 29 & 17 & $0 \cdot 5862$ \\
\hline & 2 & 18 & 20 & $1 \cdot 1111$ & 22 & 27 & 1.2273 \\
\hline & 3 & 11 & 15 & 1.3636 & 19 & 22 & $1 \cdot 1579$ \\
\hline & 4 & 10 & 11 & $1 \cdot 1000$ & 16 & 24 & $1 \cdot 5000$ \\
\hline & 5 & 6 & 6 & 1.0000 & 14 & 18 & $1 \cdot 2857$ \\
\hline & 6 & 2 & 3 & $1 \cdot 5000$ & 10 & 13 & $1 \cdot 3000$ \\
\hline & 7 & 2 & 3 & $1 \cdot 5000$ & 8 & 10 & $1 \cdot 2500$ \\
\hline & 8 & 2 & 4 & $2 \cdot 0000$ & 5 & 9 & $1 \cdot 8000$ \\
\hline & 9 & 2 & 2 & 1.0000 & 3 & 2 & 0.6667 \\
\hline & 10 & 2 & 3 & $1 \cdot 5000$ & 1 & 1 & 1.0000 \\
\hline & 11 & 1 & 2 & $2 \cdot 0000$ & 1 & 2 & $2 \cdot 0000$ \\
\hline & 12 & 1 & 0 & $0 \cdot 0000$ & 1 & 1 & $1 \cdot 0000$ \\
\hline & 13 & 1 & 2 & $2 \cdot 00 \mathrm{CO}$ & 1 & 2 & $2 \cdot 0000$ \\
\hline & 14 & - & - & - & 1 & 1 & 1.0000 \\
\hline \multirow[t]{14}{*}{ I\&DI } & 1 & 71 & 58 & $0 \cdot 8169$ & 70 & 63 & 0.9000 \\
\hline & 2 & 48 & 63 & 1.3125 & 54 & 63 & $1 \cdot 1667$ \\
\hline & 3 & 40 & 37 & 0.9250 & 43 & 54 & 1.2558 \\
\hline & 4 & 30 & 39 & $1 \cdot 3000$ & 33 & 46 & 1.3939 \\
\hline & 5 & 24 & 30 & $1 \cdot 2500$ & 25 & 30 & $1 \cdot 2000$ \\
\hline & 6 & 19 & 28 & 1.4737 & 18 & 32 & 1.7778 \\
\hline & 7 & 12 & 20 & 1.6667 & 13 & 22 & $1 \cdot 6923$ \\
\hline & 8 & 8 & 11 & 1.3750 & 8 & 14 & $1 \cdot 7500$ \\
\hline & 9 & 5 & 10 & $2 \cdot 0000$ & 5 & 10 & $2 \cdot 0000$ \\
\hline & 10 & 2 & 2 & 1.0000 & 4 & 5 & $1 \cdot 2500$ \\
\hline & 11 & 2 & 4 & $2 \cdot 0000$ & 3 & 4 & $1 \cdot 3333$ \\
\hline & 12 & 1 & 2 & $2 \cdot 0000$ & 2 & 2 & $1 \cdot 0000$ \\
\hline & 13 & - & - & - & 2 & 4 & $2 \cdot 0000$ \\
\hline & 14 & - & - & - & 1 & 2 & $2 \cdot 0000$ \\
\hline \multirow[t]{9}{*}{ Dark } & 1 & 32 & 28 & $0 \cdot 8750$ & 24 & 23 & 0.9583 \\
\hline & 2 & 24 & 31 & 1.2917 & 19 & 23 & $1 \cdot 2105$ \\
\hline & 3 & 22 & 34 & 1.5454 & 15 & 19 & 1.2667 \\
\hline & 4 & 20 & 31 & 1.5500 & 10 & 13 & $1 \cdot 3000$ \\
\hline & 5 & 15 & 25 & 1.6667 & 9 & 13 & 1.4444 \\
\hline & 6 & 11 & 14 & 1.2727 & 5 & 6 & 1.2000 \\
\hline & 7 & 8 & 13 & 1.6250 & 3 & 6 & $2 \cdot 0000$ \\
\hline & 8 & 5 & 9 & 1.8000 & 2 & 3 & 1.5000 \\
\hline & 9 & 3 & 4 & 1.3333 & 1 & 2 & $2 \cdot 0000$ \\
\hline
\end{tabular}

In the first column of the table referring to phase, the symbol $I+D I$ refers to intermediate and dark-intermediate birds. The column Exp. refers to breeding experience in years from the first year the birds bred in the colony. Sum and Mean refer to the total and mean numbers of chicks produced.

The factor $n_{1} /\left(n_{11}+n_{12}\right)$ corrects for the bias in the use of $n_{2} / n_{1}$ as an estimate of $l_{2} / l_{1}$. In general, we have for a total of $t$ years

$$
l_{x} / l_{1}=\left(n_{x} / n_{1}\right)\left\{n_{1} /\left(n_{11}+n_{12}+\ldots+n_{1 t-x+1}\right)\right\} \text {. }
$$

If the age distribution is constant, the correction factor is equal to the total number of birds in all years divided by the number of birds of which the birds who are $x$ years old could have been survivors. Table 2 shows the numbers of pairs of birds from 1948 to 1962 and the correction factors to be applied. 
TABLE 2

Pairs of birds in colony and factors to correct for bias in age distribution

$\begin{array}{ccccc}\text { Year } & \begin{array}{c}\text { No. of } \\ \text { pairs }\end{array} & \begin{array}{c}\text { Cumulative } \\ \text { no. of pairs }\end{array} & \begin{array}{c}\text { Correction } \\ \text { factor }\end{array} & \begin{array}{c}\text { Age to which } \\ \text { correction } \\ \text { factor applies }\end{array} \\ 1948 & 15 & 15 & - & - \\ 1949 & 20 & 35 & 18 \cdot 9714 & 14 \\ 1950 & 22 & 57 & 11 \cdot 6491 & 13 \\ 1951 & 26 & 83 & 8 \cdot 0000 & 12 \\ 1952 & 32 & 115 & 5 \cdot 7739 & 11 \\ 1953 & 34 & 149 & 4 \cdot 4564 & 10 \\ 1954 & 34 & 183 & 3 \cdot 6284 & 9 \\ 1955 & 44 & 227 & 2 \cdot 9251 & 8 \\ 1956 & 52 & 279 & 2 \cdot 3799 & 7 \\ 1957 & 56 & 335 & 1 \cdot 9821 & 6 \\ 1958 & 61 & 396 & 1 \cdot 6768 & 5 \\ 1959 & 65 & 461 & 1 \cdot 4403 & 4 \\ 1960 & 65 & 526 & 1 \cdot 2624 & 3 \\ 1961 & 67 & 593 & 1 \cdot 1197 & 2 \\ 1962 & 71 & 664 & 1 \cdot 0000 & 1\end{array}$

From the data given in table 1, we can only calculate the mean age of birds from the year when they first bred, for we have no data on the numbers dying before maturity. However, by catching adult birds who were ringed as chicks, we do know the ages of birds breeding for the first time. And we can then calculate the probabilities that the birds will survive up to the time they first breed-the values of $l_{1}$ for each of the phases-from the probability given by O'Donald, Wedd and Davis that they will survive from one year to the next. These data are shown in table 3. The differences

TABLE 3

Ages of birds breeding for the first time in the colony

\begin{tabular}{|c|c|c|c|c|c|c|c|c|}
\hline \multirow[b]{2}{*}{ Phase } & \multicolumn{5}{|c|}{ Age at first breeding } & \multirow[b]{2}{*}{ Total } & \multirow{2}{*}{$\begin{array}{c}\text { Mean } \\
\text { age }\end{array}$} & \multirow{2}{*}{$\begin{array}{l}\text { Prob. of } \\
\text { surviving } \\
\text { to breed }\end{array}$} \\
\hline & 3 & 4 & 5 & 6 & 7 & & & \\
\hline Pale & 6 & 5 & 1 & 2 & - & 14 & $3 \cdot 929$ & $0 \cdot 4277$ \\
\hline Intermediate & - & 16 & 8 & 2 & 1 & 27 & 4.556 & $0 \cdot 3682$ \\
\hline Dark & 1 & 5 & 3 & 2 & - & 11 & $4 \cdot 545$ & $0 \cdot 3709$ \\
\hline All phases & 7 & 26 & 12 & 6 & 1 & 52 & $4 \cdot 385$ & $0 \cdot 3848$ \\
\hline
\end{tabular}

Both sexes are lumped together in this table because they both breed at about the same age if they are of the same phase. Pales breed very significantly earlier than the others $\left(\chi^{2}=14.28\right.$ with two degrees of freedom). The probabilities of surviving to breed were calculated by assuming that immature birds have the same probabilities of survival from one year to the next as the adults. This assumption is likely to be true for birds more than one year old and it gives the observed mean intrinsic rate of increase fairly closely. Since adult birds have regularly been shot on Fair Isle, their probability of survival has been reduced by a considerable factor: their 20 per cent annual adult mortality is very high for sea birds. It is about what we should expect the mortality of newly fledged birds to be. We also assumed that immature birds do not differ in their chances of survival. Our estimates of the selective differences of the phases would be too small if there were real differences in the mortalities of immature birds. 
between the values for intermediates and darks in the table are not significant, and the following calculations use the average value for intermediates and darks. The mean breeding age, $T$, and mean reproductive rate, $R_{0}$, can then be obtained. Hence $R_{1}=R_{0} T$ and we calculate the intrinsic rate of increase, $r$, by the equation

$$
r=\left(R_{0}-1\right) / R_{1},
$$

which is an approximate solution (assuming $r$ is small) of the fundamental demographic equation

$$
\sum_{x} e^{-r x} l_{x} b_{x}=1
$$

If $r_{1}$ and $r_{2}$ are the intrinsic rates of increase of two different phases, then their relative fitness is estimated by the ratio

$$
\exp \left(r_{1} \bar{T}\right) / \exp \left(r_{2} \bar{T}\right)=1-s \quad\left(r_{1}<r_{2}\right),
$$

where $T$ is the mean breeding age of all birds-an estimate of the mean generation time-and $s$ is the selective coefficient. Table 4 gives the values of the reproductive rates, intrinsic rates of increase and selective coefficients calculated from the values given in tables 1,2 and 3 . The average intrinsic rates of increase of males and females are not exactly equal, partly because they are not derived from the same pairs of birds and partly because of the use of the correction for bias.

\begin{tabular}{|c|c|c|c|c|c|}
\hline Phase and sex & $\begin{array}{c}\text { Mean age } \\
\text { of breeding } \\
T\end{array}$ & $\begin{array}{c}\text { Reproductive } \\
\text { rate } \\
R_{0}\end{array}$ & $\begin{array}{c}\text { Intrinsic } \\
\text { rate of } \\
\text { increase } \\
r\end{array}$ & $\begin{array}{c}\text { Fitness } \\
w\end{array}$ & $\begin{array}{c}\text { Selective } \\
\text { coefficient } \\
s\end{array}$ \\
\hline Pale males & $9 \cdot 319$ & $1 \cdot 580$ & 0.0394 & $1 \cdot 449$ & 0.094 \\
\hline Inter males & $8 \cdot 741$ & $1 \cdot 303$ & 0.0266 & $1 \cdot 284$ & $0 \cdot 197$ \\
\hline Dark males & $8 \cdot 141$ & $1 \cdot 682$ & $0 \cdot 0498$ & 1.599 & 0 \\
\hline All males & $8 \cdot 594$ & 1.471 & 0.0372 & $1 \cdot 377$ & - \\
\hline Pale fe & $9 \cdot 441$ & $2 \cdot 132$ & 0.0562 & 1.699 & 0 \\
\hline Inter females & $9 \cdot 840$ & $1 \cdot 732$ & 0.0429 & $1 \cdot 499$ & 0.118 \\
\hline Dark females & $7 \cdot 651$ & $1 \cdot 195$ & 0.0213 & $1 \cdot 223$ & $0 \cdot 280$ \\
\hline All females & $9 \cdot 422$ & 1.723 & 0.0445 & 1.522 & - \\
\hline
\end{tabular}

TABLE 4

Calculation of the overall fitnesses of the phases of the Arctic Skua

A small part of the overall advantage of pale depends on the few, long-lived pale birds: the correction for bias increases their effect on the mean reproductive rate. If the correction for bias is kept constant for the older birds, however, the estimated selection for pale is only slightly reduced. The mean intrinsic rate of increase is reduced to 0.04046 -almost exactly the observed rate of increase in the population.

\section{The components of Selegtion}

The sexual component of the selection can be estimated simply by the differences in the reproductive rates in so far as they differ as a result of the mating preferences. Suppose the number of new pairs is $n$, while $\mathcal{N}$ is the total number of pairs. If $b_{D}$ and $b_{P}$ are the average numbers of chicks 
fledged by dark and pale males in new pairs and differ only as a result of sexual selection, then for dark males the reproductive rate determined by the sexual component of the selection is

$$
R_{0(D)}=b_{D} n+B(N-n)
$$

and for pale males it is

$$
R_{0(P)}=b_{P} n+B(N-n),
$$

where $B$ is the average number of chicks fledged by all other pairs. Thus we obtain the sexual selective coefficient of the pale males as follows.

$$
\begin{aligned}
s_{P} & =1-R_{0(P)} / R_{0(D)} \\
& =\frac{\frac{n}{N}\left(1-\frac{b_{P}}{b_{D}}\right)}{\frac{n}{N}+\frac{B}{b_{D}}\left(1-\frac{n}{N}\right)} .
\end{aligned}
$$

If the relative sexual disadvantage of pales in new pairs is measured by

$$
S_{P}=1-b_{P} / b_{D}
$$

then the overall sexual selective coefficient is approximately

$$
s_{P}=\frac{n}{N} S_{P}
$$

O'Donald, Wedd and Davis used this approximate formula to estimate the sexual disadvantage of intermediate and pale males compared to darks. They obtained the values

$$
\begin{aligned}
& s_{I}=0.026 \text { for intermediates } \\
& s_{P}=0.070 \text { for pales. }
\end{aligned}
$$

These are close to the more exact values

$$
\begin{aligned}
& s_{I}=0.024 \\
& s_{P}=0.069 .
\end{aligned}
$$

The major component of the selection, however, is the earlier maturity of the pale birds. This shortens their mean breeding age and increases their chance of surviving to breed. O'Donald, Wedd and Davis were not aware of this factor when they used the mean fledging success to estimate the selective coefficients of the phases. To estimate the effect of the different ages of maturity, the data for the females in table 1 were lumped: the average generation time is then found for the pales and the rest allowing only for the different mean ages when the pales and the intermediates and darks first breed. The average reproductive rates are found allowing only for the differences in the probabilities of surviving to breed. Table 5 shows these calculations and the fitnesses and selective coefficients resulting from the differences in the ages when the birds first breed. This component of selection, favouring the pales because of their earlier maturity, thus more than compensates for the sexual selection in favour of dark males. 
TABLE 5

Component of selection resulting from differences in age when birds first breed

$\begin{array}{llc} & \text { females } & \text { dark females } \\ \text { Generation time } T & 8.966 & 9.590 \\ \text { Reproductive rate } R_{0} & 1.916 & 1.653 \\ \text { Intrinsic rate of increase } r & 0.0533 & 0.0412 \\ \text { Fitness } w & 1.653 & 1.474 \\ \text { Selective coefficient } s & 0 & 0.108\end{array}$

The components of selection are neither exactly additive nor exactly multiplicative in their contribution to the total selection. This follows because they are not simple viabilities.

\section{Predictions of changes in population size and gene frequency}

The changes in population size and gene frequency can be predicted from the intrinsic rates of increase and fitnesses given in table 4. In 1962 there were 71 pairs of Arctic Skuas on Fair Isle. No intensive fieldwork on the skuas was done until J. W. F. Davis and P. O'Donald began further work in 1973. Thus eleven years had elapsed and in this time the population had increased from 71 to 106 pairs of birds. Hence $\exp (r T)=106 / 71$, where $T=11$. Taking the average value of $r$ for all phases of females from table 4 , we get $\exp (r T)=1.632$ compared to the observed value of 1.493. The predicted size of the population is 116 in 1973. Although this prediction agrees fairly well with the observed number of pairs, migration, which could be an important factor, has been ignored in the calculations. We have not yet been able to estimate the rate of migration, but a number of the breeding adults on Fair Isle were probably reared as chicks on other colonies. This will not necessarily alter the prediction of the change of population size if there is the same intrinsic rate of increase throughout the area where migration is taking place between skua colonies. Work is now being carried out on other colonies as well as Fair Isle, in order to estimate the migration by ringing chicks and recapturing adults.

Birds reared on Fair Isle who have returned there to breed provide data, shown in table 6 , on the genetics of the phases. Intermediates are mainly heterozygous; but some misclassification is likely, for there is a more or less continuous range of phenotypic variation from intermediate to dark. Pales are completely distinct from the other phases. With the knowledge of the genetics of the phases, we can predict the consequences of selection. Table 7 gives the computed values of the gene frequency of the allele for dark in successive generations. After 50 generations the dark phase should have largely disappeared. In the first generation of selection, the predicted gene frequency is 0.5039 , which is the mean of the frequencies predicted for males and females. We now know the actual frequency in the next generation. In 1973 the numbers of the genotypes were as follows: 46 darks, 124 intermediates and 40 pales, giving a mean frequency of 0.5143 . When observed and predicted frequencies are compared, $\chi^{2}=0.182$ for one degree of freedom. The gene frequency is higher in the males than in the females, which also agrees very closely with the predictions.

$35 / 1-F$ 
TABLE 6

Inheritance of colour phase in the Arctic Skua

\begin{tabular}{|c|c|c|c|c|}
\hline \multirow[b]{2}{*}{ Mating } & \multicolumn{4}{|c|}{ Colour phase of offspring } \\
\hline & $\mathbf{P}$ & I & DI & D \\
\hline $\mathbf{P} \times \mathbf{P}$ & 5 & - & - & - \\
\hline$P \times I$ & 5 & 6 & 2 & - \\
\hline $\mathrm{P} \times \mathrm{DI}$ & 1 & 2 & - & - \\
\hline$P \times D$ & - & 4 & 2 & - \\
\hline $\mathrm{I} \times \mathrm{I}$ & 3 & 4 & 1 & 1 \\
\hline $\mathrm{I} \times \mathrm{DI}$ & 1 & 4 & 1 & - \\
\hline $\mathrm{I} \times \mathrm{D}$ & - & 5 & 1 & 7 \\
\hline $\mathrm{DI} \times \mathrm{DI}$ & 1 & 1 & - & 1 \\
\hline $\mathrm{DI} \times \mathrm{D}$ & - & 2 & 1 & 4 \\
\hline $\mathrm{D} \times \mathrm{D}$ & - & - & - & 2 \\
\hline
\end{tabular}

The table shows the colour phase of birds who have returned to breed in the colony on Fair Isle. $\mathbf{P}$ refers to pale, I to intermediate, DI to dark-intermediate and D to dark. The data span the years from 1948 to 1974.

The polymorphism of colour phases in the Arctic Skua may thus be a transient one as pale phases increase in frequency. On this theory the dark phase was primitive. In the Pomarine and Long-tailed Skuas, which are mainly pale, the selection for pale must have started earlier or been more intense than in the Arctic Skua. The Pomarine and Long-tailed Skuas are both more northerly in their breeding range than the Arctic Skua. The Arctic Skua also has a high proportion of pale phases in its more northerly colonies, suggesting that selection in favour of pale is more intense further north.

O'Donald $(1972,1973,1974)$ showed that sexual selection, when it is determined by variations in fitness at breeding time, is necessarily frequencydependent. The sexual selection coefficient will therefore change if the pale phase increases in frequency. Hence the total selective coefficients

TABLE 7

Predicted gene frequencies in successive generations

\begin{tabular}{ccc} 
Generation & \multicolumn{2}{c}{ Gene frequency of allele for dark } \\
\cline { 2 - 3 } 1 & In females & In males \\
2 & $0 \cdot 4764$ & 0.5314 \\
3 & $0 \cdot 4637$ & $0 \cdot 5175$ \\
4 & $0 \cdot 4507$ & $0 \cdot 5031$ \\
5 & $0 \cdot 4375$ & $0 \cdot 4882$ \\
10 & $0 \cdot 4239$ & $0 \cdot 4729$ \\
20 & $0 \cdot 3518$ & $0 \cdot 3908$ \\
30 & $0 \cdot 2014$ & $0 \cdot 2179$ \\
40 & $0 \cdot 0862$ & $0 \cdot 0898$ \\
50 & $0 \cdot 0295$ & $0 \cdot 0300$ \\
& $0 \cdot 0091$ & $0 \cdot 0091$
\end{tabular}

Since the fitness as given by the expression $\exp (r T)$ is only an approximate estimate of the fitness from one complete generation to the next, the values in this table will be subject to increasing errors with increasing generations. Only the first few generations can actually be observed, however. 
will change. In the absence of other selective forces, the female mating preferences for dark and intermediate males would produce a stable polymorphism (O'Donald, 1974). However, they are of a magnitude that only produces a small frequency-dependent effect. It is unlikely therefore that the sexual selective coefficients would balance the natural selection in favour of pale at any stage during the evolution. Pale should eventually replace dark.

Acknowledgment.-We are grateful to the Natural Environment Research Council for a Research Grant, No. GR3/1897, which financed the work described in this paper.

\section{ReFERENCES}

BERRY, R. J., AND DAVTS, P. E. 1970. Polymorphism and behaviour in the Arctic Skua (Stercorarius parasiticus (L.)). Proc. Roy. Soc., B, 175, 255-267.

CAvalli-sforza, L. L., AND Bodmer, w. F. 1971. The Genetics of Human Populations. W. H. Freeman and Co., San Francisco.

DARwin, c. 1871. The Descent of Man and Selection in Relation to Sex. John Murray, London. o'DONALD, P. 1972. Natural selection of reproductive rates and breeding times and its effect on sexual selection. Amer. Nat., 106, 368-379.

o'DONALD, P. 1973. Frequency-dependent sexual selection as a result of variations in fitness at breeding time. Heredity, 30, 351-368.

o'DonAld, P. 1974. Polymorphisms maintained by sexual selection in monogamous species of birds. Heredity, 32, 1-10.

o'DonAld, P., WEDD, N. S., AND DAvis, J. W. F. 1974. Mating preferences and sexual selection in the Arctic Skua. Heredity, 33, 1-16.

\section{Note Added in Proof}

The approximate solutions of Lotka's equation used in this paper to estimate the overall selective coefficients give values which are consistently too small. More accurate solutions can be calculated from the statistics $R_{j}=\Sigma x^{j} l_{x} b_{x}$. The following estimates of the overall selective coefficients are then obtained.

$\begin{array}{lccc} & \text { Pale phase } & \text { Intermediate phase } & \text { Dark phase } \\ \text { Males } & 0 \cdot 11 & 0.28 & 0 \\ \text { Females } & 0 & 0.30 & 0.49\end{array}$

Details of these calculations will be given in a forthcoming paper. 